Retos, I0(19), 2020

\title{
Buen gobierno local y rendición de cuentas en España
}

\section{Local good governance and accountability in Spain}

Dr. Roberto Fernández Llera es Doctor por la Universidad de Oviedo y síndico mayor de la Sindicatura de Cuentas del Principado de Asturias (España) (robertofll@sindicastur.es) (http://orcid.org/0000-0003-3096-1905)

\begin{abstract}
Resumen
La rendición de cuentas es una de las exigencias fundamentales dentro de los parámetros generales del buen gobierno y de la transparencia. El sector público local en España ofrece un caso de estudio especialmente interesante, por la amplitud de la muestra a analizar y por los cambios normativos de los últimos años. Para ello, se examina la regulación del buen gobierno en la normativa española, con especial atención al sector público local y al grado efectivo de cumplimiento del deber de rendición de cuentas ante las instituciones de control externo. La metodología empleada combina el análisis jurídico con el de los principales indicadores del ciclo presupuestario. La principal conclusión señala el bajo grado de cumplimiento de las obligaciones legales en los municipios españoles. Las causas son múltiples y variadas, algunas de las cuales está tratando de combatir la reciente legislación de transparencia y buen gobierno, tanto estatal como autonómica. En el sector público local se precisa una mayor claridad en las normas y procedimientos internos que permitan cumplir con mayor eficacia las exigencias legales, adaptándose en particular al tamaño de cada administración concernida, dada la atomización municipal. La difusión y la comunicación de los resultados es otra variable fundamental para impulsar el cumplimiento de estas obligaciones. En última instancia, antes graves y reiterados incumplimientos, podrían ser eficaces las medidas coercitivas y sanciones que han recomendado las instituciones de control externo.
\end{abstract}

\begin{abstract}
Accountability is one of the fundamental requirements within the general parameters of good governance and transparency. Local government in Spain offers a particularly interesting case study, due to the breadth of the sample to be analyzed and the regulatory changes of recent years. For this, the Spanish regulation of good governance is examined, with special attention to local government and the effective degree of compliance with the duty of accountability to external audit institutions. The methodology used combines legal and budgetary analysis of the main indicators of the budget cycle. The main conclusion points out the low degree of compliance with legal obligations in Spanish local government, mainly municipalities. The causes are multiple and varied, some of which are trying to combat the recent legislation on transparency and good governance, both central and regional. In the local government, greater clarity is needed in the internal rules and procedures that make it possible to comply more effectively with legal requirements, adapting in particular to the size of each administration concerned, given the municipal atomization in Spain. The dissemination and communication of results is another fundamental variable to promote compliance with these obligations. Ultimately, in the face of serious and repeated breaches, coercive measures and sanctions would be an effective measure, as the audit institutions have recommended.
\end{abstract}

\section{Palabras clave I keywords}

Buen gobierno, transparencia, rendición de cuentas, control externo, gobierno local, España, fiscalización, Tribunal de Cuentas.

Good governance, transparency, accountability, external control, local government, Spain, audit, Court of Auditors.

Cómo citar: Fernández Llera, R. (2020). Buen gobierno local y rendición de cuentas en España. Retos Revista de Ciencias de la Administración y Economía, 10(19), 29-44. https://doi. org/10.17163/ret.n19.2020.02 


\section{Introducción}

El Diccionario de la lengua española define la ética en una de sus acepciones como el "conjunto de normas morales que rigen la conducta de la persona en cualquier ámbito de la vida". La responsabilidad alude en términos jurídicos a la "capacidad existente en todo sujeto activo de derecho para reconocer y aceptar las consecuencias de un hecho realizado libremente". Una tercera noción, la gobernanza, es el "arte o manera de gobernar que se propone como objetivo el logro de un desarrollo económico, social e institucional duradero, promoviendo un sano equilibrio entre el Estado, la sociedad civil y el mercado de la economía”. La síntesis dentro del sector público conduce al principio de transparencia, al deber de rendición de cuentas y, por extensión, al concepto amplio de buen gobierno y a la necesidad de promover la calidad institucional.

Aunque habría antecedentes mucho más remotos (Villoria Mendieta, 2014), un alusivo punto de partida sería la aspiración de buen gobierno que quedó reflejada hace siete siglos en la pintura italiana, siendo una excelente muestra la alegoría de Lorenzetti, sita en el Palazzo Comunale de Siena ${ }^{1}$ y descrita así por García Pelayo (2009, p. 1239):

La justicia, iluminada por la sabiduría, integra a los hombres en la concordia, y desde ella en la corporación o cuerpo místico de la comuna bajo el gobierno impersonal y abstracto del bien común, el cual, constantemente inspirado por las virtudes políticas, asegura un orden pacífico del que se excluye toda violencia, salvo a los malhechores, obtiene sin presión los impuestos de los ciudadanos y la sumisión de los señores del campo.

Saltando casi 500 años desde aquella referencia pictórica, también es destacable por su simbolismo el tenor del artículo 6 de la Constitución Española de 1812, cuando en su literalidad se obligaba a los ciudadanos españoles al "amor de la patria" y a "ser justos y benéficos".

Ya en nuestros días, la Comisión Europea (2001) abrió un camino de amplio recorrido bajo el concepto de gobernanza, debajo del cual se cobijan ideas como apertura (transparencia y comunicación de las actuaciones públicas), participación (implicación sistemática de la ciudadanía), responsabilidad (clarificación del papel de cada agente), eficacia (decisiones a la escala y en el momento apropiados, produciendo los resultados apetecidos) y coherencia (entre políticas diversas). En el momento actual, superados algunos vaivenes históricos e incluso modas pasajeras (Irwin, 2013), queda claro el marco general en los Objetivos de Desarrollo Sostenible de Naciones Unidas ${ }^{2}$, los cuales abogan por una concepción integral y transversal de la ética, la transparencia y el buen gobierno, siendo incluso una meta explícita (número 16.6) para llegar a "crear a todos los niveles instituciones eficaces y transparentes que rindan cuentas”.

En lo que se refiere a la transparencia más en concreto, nos debemos referir en todo momento a la que resulta suficiente y útil, huyendo de las zonas de oscuridad o impunidad, pero también del caudal excesivo de información sin orden, concierto, sistematización ni control. En España, las numerosas lagunas informativas y la dis-

1 A mayor abundamiento, resultan también esenciales los ensayos de Skinner (2009) y González García (2016).

2 Más información en el sitio web de Naciones Unidas: http://bit.ly/2MSghqh. 
persión de información valiosa han sido tradicionales fuentes de indisciplina fiscal (Barea Tejeiro, 1997). Aún hoy, los datos del Fondo Monetario Internacional (Wang et al., 2015, p. 10) muestran que España sigue siendo uno de los países del mundo donde el grado de exhaustividad y comprensibilidad de sus estadísticas sobre finanzas públicas es más reducido. No hablamos, por tanto, de la transparencia que se traduce en una multitud de datos, cifras e informes de escaso valor añadido, reducida accesibilidad y bajo interés objetivo (salvo para ciertos colectivos minoritarios). Si así fuese, la transparencia podría degenerar en lo que se ha dado en llamar sobrecarga informativa o - utilizando neologismos bastardos-infoxicación y tramparencia.

En España, la legislación de estabilidad presupuestaria de 2001 supuso un aldabonazo en materia de transparencia pública, al colocar este principio como una de las claves al servicio de la estabilidad presupuestaria. Es cierto que tampoco fue una absoluta novedad, puesto que este principio general ya estaba recogido en la legislación administrativa básica y en algunas normas sectoriales relativas a urbanismo, subvenciones, personal, medioambiente o contratación pública, entre otras. Sin embargo, toda esa legislación tenía un enfoque parcial e incluso adolecía de un excesivo voluntarismo, sin que siquiera en muchos casos se previesen sanciones o medidas por incumplimiento, y sin que el ciudadano tuviese garantizado plenamente su derecho de acceso a la información pública, en el marco del artículo 105 de la Constitución Española y de la concordante normativa supranacional europea. Ese vacío lo vendrían a cubrir dos normas fundamentales.

De un lado, el primer gran cambio llegaría en 2012 con la Ley Orgánica 2/2012, de 27 de abril, de Estabilidad Presupuestaria y Sostenibilidad Financiera (LOEPSF), la cual supuso un indudable refuerzo de la transparencia como paradigma de gestión pública, en el marco más amplio del nuevo principio constitucional de estabilidad presupuestaria, de obligado cumplimiento para todos los niveles de gobierno y para todos los entes integrantes del sector público.

El segundo gran hito vino dado por la Ley 19/2013, de 9 de diciembre, de transparencia, acceso a la información pública y buen gobierno (LTAIBG), cuyas tres vertientes quedan claras ya en su mismo título. En su preámbulo ${ }^{3}$ se reconoce el retraso regulador español en las materias de transparencia y derecho de acceso a la información pública ("España no podía permanecer por más tiempo al margen”), aunque al mismo tiempo se declara que la nueva ley "no parte de la nada ni colma un vacío absoluto, sino que ahonda en lo ya conseguido, supliendo sus carencias, subsanando sus deficiencias y creando un marco jurídico acorde con los tiempos y los intereses ciudadanos". Lo cierto es que el efecto combinado de la LOEPSF y la LTAIBG ha supuesto una mejora sustancial del grado de transparencia de las instituciones públicas en España, entre las que el gobierno local no ha sido una excepción. Algunos estudios empíricos recientes han ido constatando este significativo avance, en particular en el ámbito de la información económico-financiera y presupuestaria,

3 El texto consolidado se encuentra en https://bit.ly/36ff9ok (1 de octubre de 2019). 
indagando asimismo en los determinantes y las causas diferenciales de dicha transparencia, con resultados dispares. ${ }^{4}$

El legislador general optó también por incorporar en un mismo cuerpo legal la normativa sobre buen gobierno, de tal forma que — de nuevo citando su preámbulo"principios meramente programáticos y sin fuerza jurídica se incorporan a una norma con rango de ley y pasan a informar la interpretación y aplicación de un régimen sancionador al que se encuentran sujetos todos los responsables públicos", aludiendo además a la "ejemplaridad" en su conducta. De este modo, se deja atrás un planteamiento tradicional de ética del servidor público basada en el llamado "derecho blando" (soft law), difuminado en códigos de conducta o deontológicos, recomendaciones de buenas prácticas o hasta el uso de la pura costumbre como fuente de derecho y rutina de funcionamiento. Desde entonces, será la ley (hard law) la que obligue a los altos cargos y asimilados a modificar comportamientos y conductas (Descalzo González, 2017), en aplicación similar a lo que venía sucediendo para los empleados públicos por su propia normativa funcionarial, laboral o estatutaria (García Jiménez, 2018). De otro modo, se podrán imponer nuevas sanciones específicas por incurrir en conflictos de interés, inadecuada gestión económico-presupuestaria o infracciones disciplinarias.

Debe subrayarse que a la fecha, la práctica totalidad de las comunidades autónomas tiene en vigor sus respectivas leyes de transparencia y/o buen gobierno, ${ }^{5}$ con el común denominador de ampliar las exigencias de la normativa básica estatal, aunque en algunos casos con escasa mejora efectiva y no siempre con aplicación al respectivo sector público local (Ridao Martín, 2014; INAP, 2016). A ellas se añaden otras normas reglamentarias y de desarrollo, así como disposiciones de "derecho blando" en las distintas entidades o agrupaciones del ámbito autonómico o local. Se podría decir que, tras haber sido España uno de los últimos países de la Unión Europea y de la OCDE en contar con una legislación específica de transparencia, así como uno de los pocos que la funden en un mismo texto legal con la normativa sobre buen gobierno, en estos momentos se produce justo la situación contraria de inflación legislativa (Bassols Coma, 2015).

El objetivo de este trabajo es analizar el buen gobierno en la normativa española, con especial atención al sector público local y a una de sus manifestaciones más concretas, como es la rendición de cuentas. En la sección 2 se repasa la regulación del buen gobierno en la legislación estatal básica, de aplicación en toda España. En la sección 3 se analiza el estado de la rendición de cuentas de las entidades locales, desde el punto de vista normativo y de su efectivo cumplimento. La última sección concluye.

4 Sin ánimo de exhaustividad, se puede citar los trabajos de Serrano-Cinca et al. (2009), Cárcaba García y García-García (2010), Guillamón et al. (2011), Esteller-Moré y Polo Otero (2012), Albalate del Sol (2013), Caamaño-Alegre et al. (2013), Frías Aceituno et al. (2013), García-Sánchez et al. (2013), Vila i Vila (2013), Campos Acuña y Caamaño Alegre (2015), Suárez Pandiello y Fernández Llera (2017) y Tejedo-Romero y Ferraz Esteves Araujo (2018). Asimismo, Arapis y Reitano (2018) ofrecen una valiosa referencia internacional (59 países) y Bearfield y Bowman (2017) para el nivel de gobierno local.

5 El Consejo de Transparencia y Buen Gobierno (https://bit.ly/2MU6vEr) publica la información desagregada y actualizada. 


\section{Desarrollo del buen gobierno en la legislación básica española}

La LTAIBG establece dos condiciones previas y sendos listados con principios de buen gobierno (generales y de actuación), exigibles de las personas que ostentan la condición de alto cargo o asimilado en todos los niveles de gobierno. En el ámbito local se incluyen quienes tengan la consideración de alto cargo o asimilado según la normativa autonómica o local de aplicación, incluidos los miembros de las juntas de gobierno, aunque sin afectar en ningún caso a la condición de cargo electo que pudieran ostentar. Los sujetos concernidos deberán adecuar su actividad a dichos principios y, al mismo tiempo, estos informarán la interpretación y la aplicación del régimen sancionador por incumplimiento. Una crítica principal a estos principios legales de buen gobierno es por su vaguedad, al menos, por tres motivos. Primero, por la ociosa remisión a la observancia obligatoria con respecto a lo dispuesto en la Constitución Española y en el resto del ordenamiento jurídico, con particular respeto a los derechos fundamentales y a las libertades públicas. Segundo, por la no menos obvia referencia a esos principios de buen gobierno para que informen sobre la interpretación y la aplicación del régimen sancionador. Tercero, por la propia indeterminación intrínseca de los principios que se enuncian, algunos de los cuales ya estaban en el ordenamiento jurídico (incluida la transparencia) o formaban parte de normas elementales o códigos de buena conducta.

La principal novedad de la LTAIBG se encuentra en la tipificación de las infracciones muy graves en materia de gestión económico-presupuestaria, las que por simplicidad podrían denominarse como de "buen gobierno económico" (Palomar Olmeda, 2014). El listado no parece seguir un particular orden, si bien muchas de esas conductas culposas traen causa directa de incumplimientos de la normativa general presupuestaria o de la LOEPSF. La inexistente o defectuosa rendición de cuentas sería una más de las infracciones por vulneración de la normativa general presupuestaria, si bien por su especial estatus parece adecuado ubicarla con una categoría propia.

Las infracciones serán sancionadas con la declaración del incumplimiento y su publicación en el correspondiente boletín oficial para general conocimiento, así como con la no percepción de la indemnización para el caso de cese en el cargo, si estaba prevista. Además, las personas sancionadas serán también destituidas del cargo que ocupen y tendrán una inhabilitación para cualquier puesto de alto cargo o asimilado durante un periodo que puede oscilar entre cinco y diez años. Asimismo, se deberán restituir las cantidades percibidas o satisfechas indebidamente y se tendrá obligación de indemnizar a la Hacienda Pública. La responsabilidad será exigida en procedimiento administrativo, dando además conocimiento al Tribunal de Cuentas por si procediese incoación de procedimiento de responsabilidad contable, todo ello sin perjuicio de la derivación a las instancias judiciales o fiscalías oportunas, en caso de ser apreciados indicios de delito o infracción de alguna norma administrativa especial. Todas las sanciones se graduarán según el principio de proporcionalidad y criterios adicionales, como son la gravedad del peligro ocasionado, la intensidad del perjuicio causado, las consecuencias desfavorables para la Hacienda Pública o —en sentido inverso- la voluntad de subsanación y reparación. 
Opina Campos Acuña (2014, p. 23) que la legislación básica de buen gobierno, nacida como respuesta a una palpable demanda social, se ha plasmado en un régimen sancionador de compleja aplicación práctica, agravada aún más con la entrada en vigor de la ulterior legislación autonómica. Entre otros problemas de ejecución, la autora cita la posible utilización perversa o abusiva del procedimiento de denuncia ciudadana "en clave personal o política" (sic), las cuestiones de índole competencial y procedimental, o el papel de los cargos electos cuando cometan infracciones punibles. En los últimos años se ha venido a completar esa regulación con normas relativas al ejercicio de alto cargo, tanto en el ámbito estatal como en varias comunidades autónomas, casi siempre con exclusión del sector público local. La incidencia efectiva en el gobierno local no es absoluta, aunque sí se encuentran supuestos en la Ley 7/1985, de 2 de abril, Reguladora de las Bases del Régimen Local. Así, para los miembros de las corporaciones locales con dedicación exclusiva y para el personal directivo se establecen limitaciones al ejercicio de actividades privadas durante los dos años siguientes a la finalización de su mandato, autorizándose en el primer caso compensaciones económicas cuando no puedan desempeñar su actividad profesional, ni perciban retribuciones económicas por otras actividades. Otro ejemplo de pretendido buen gobierno son los límites en las retribuciones de los miembros de las corporaciones locales y del personal al servicio de las entidades locales, así como las limitaciones en el número de cargos públicos que puede tener dedicación exclusiva.

\section{Tabla 1. Código de Buen Gobierno Local de la FEMP}

\begin{tabular}{|l|l|}
\hline \multirow{*}{*}{ Objetivos } & - Integrar la dimensión ética en el funcionamiento de las entidades locales \\
- Incorporar las estrategias de participación ciudadana y gobierno abierto \\
- Definir las líneas básicas que deben presidir la gestión pública local \\
- Reforzar los estándares de conducta en el ejercicio de las responsabilida- \\
- des públicas \\
\\
- Delimitar pautas para la adecuadas relación entre los ámbitos de gobier- \\
no y administración \\
\hline - Principios del buen gobierno local (11) \\
- Estándares de conducta para la mejora de la democracia local (14) \\
- Compromisos éticos en materia de conflictos de intereses (6) \\
- Régimen de incompatibilidades y retribuciones \\
- Gobierno y administración: relaciones entre cargos electos y empleados \\
- públicos \\
- Medidas para la mejora de la democracia participativa \\
\hline
\end{tabular}

Fuente: FEMP, 2015.

En el sector público local ha de buscarse la continuidad de la legislación de buen gobierno en los códigos de ética, conducta o buen gobierno que han aprobado las propias entidades o sus asociaciones más representativas, en particular, la Federación Española de Municipios y Provincias (FEMP) y las homólogas territoriales. Por constituir la referencia básica, en la tabla 1 se ha sintetizado el Código de 
Buen Gobierno Local de la FEMP, cuyo objetivo principal es establecer los principios a respetar en el desempeño de las responsabilidades políticas de gobierno y administración, así como las de dirección y gestión local, fijando los compromisos que reflejen los estándares de conducta recomendados y reforzando la calidad democrática de las instituciones locales. Sin duda, en el mundo local se transita cada día por una senda de ida y vuelta, desde el "derecho blando" a la ley, y viceversa.

\section{El incumplimiento de la obligación de rendición de cuentas}

Sin perjuicio de otros antecedentes aún más remotos, la rendición de cuentas locales en España hunde sus raíces históricas en las primigenias instituciones de control de la Europa bajomedieval, donde se incluían, entre otras, la Cámara de Comptos de Navarra o el Mestre Racional dentro de algunos reinos peninsulares. Con el final del Antiguo Régimen, la Declaración de los Derechos del Hombre y del Ciudadano de 1789 reconoció que "la Sociedad tiene derecho a pedir a todos sus Agentes públicos cuentas de su administración”. Ya en la etapa contemporánea, ese deber genérico se iba a ir modulando y concretando en la rendición de cuentas a las instituciones públicas de control externo ${ }^{6}$ (ICEX), no solo como una exigencia ética y democrática, sino también como unas de las grandes preocupaciones ciudadanas y prioridades políticas, más aún en los últimos años, con motivo de la llamada Gran Recesión. En consecuencia, ese deber público ha terminado por mutar en obligación, dentro de los parámetros ordinarios de la gestión presupuestaria, la transparencia y el buen gobierno. No en vano, como ha dejado claramente sentado el Tribunal de Cuentas (2014):

La rendición de cuentas constituye el mecanismo a través del cual los responsables de la entidad responden de la gestión económico-financiera desarrollada ante quienes les proporcionan sus recursos y atienden a las necesidades de información de los usuarios [de tal información]: el parlamento nacional, el Tribunal de Cuentas, las asambleas legislativas autonómicas, los órganos de control externo autonómicos, los gestores, los órganos de control interno, los usuarios de los servicios públicos, los órganos de representación política, los acreedores, los analistas económicos y financieros, los servicios de rating, las organizaciones públicas nacionales o internacionales, los contribuyentes y los ciudadanos en general.

En definitiva, la rendición de cuentas no es un mero desiderátum o un simple trámite administrativo, sino una conducta exigida a todo gestor público y responsable político, con consecuencias jurídicas —incluso personales- derivadas del incumplimiento (Teré Pérez, 2015).

La rendición de cuentas comienza con el suministro de información económico-financiera sistematizada y fiable acerca del origen y de la utilización de los recursos públicos en un determinado ámbito temporal. Obviamente, la rendición de cuentas no comienza ni se agota en ese acto de entrega de cifras y documentos, sino que lleva asociada la continua y leal colaboración entre controlador y controlado, tanto en fase previa como posterior, con el fin de facilitar el adecuado examen

6 Bajo esta denominación se designa conjuntamente en España al Tribunal de Cuentas — supremo órgano fiscalizador- y a los órganos de control externo autonómicos (https://bit.ly/2MTOKoI). 
(mediante pruebas de auditoría) y la emisión de un juicio valorativo (con opinión y recomendaciones) por parte de las ICEX, a partir de la evidencia obtenida.

De ese modo, la función principal de las ICEX es la fiscalización, entendida como el "conjunto de actuaciones del Tribunal de Cuentas [o de otra ICEX] para comprobar el sometimiento de la actividad económico-financiera del sector público a los principios de legalidad, eficacia, eficiencia, economía y, en su caso, otros de buena gestión" (Tribunal de Cuentas, 2013). Siguiendo ese criterio, el término "fiscalización" se emplea en las Normas Internacionales de las Entidades Fiscalizadoras Superiores adaptadas a España ${ }^{7}$ para designar la función constitucional, estatutaria o legalmente asignada a las ICEX, reservando el término "auditoría" a una de las técnicas —no la única- para ejercer dicha función. ${ }^{8}$

Tabla 2. Cumplimiento de plazos legales en los municipios (\% del total)

\begin{tabular}{|l|l|l|l|l|l|}
\hline & Presupuesto & Liquidación & \multicolumn{1}{|c|}{$\begin{array}{c}\text { Cuenta } \\
\text { general }^{* 3}\end{array}$} & Rendición & \multicolumn{1}{|c|}{$\begin{array}{c}\text { Municipios } \\
\text { considerados }\end{array}$} \\
\hline 2009 & $11,8 \%$ & $46,5 \%$ & $42,5 \%$ & $10,1 \%$ & 6.897 \\
\hline 2010 & $12,4 \%$ & $53,7 \%$ & $51,0 \%$ & $29,6 \%$ & 7.147 \\
\hline 2011 & $13,8 \%$ & $66,0 \%$ & $63,5 \%$ & $40,6 \%$ & 7.291 \\
\hline 2012 & $13,9 \%$ & $74,3 \%$ & $76,1 \%$ & $52,7 \%$ & 7.355 \\
\hline 2013 & $26,7 \%$ & $78,9 \%$ & $75,0 \%$ & $51,2 \%$ & 7.382 \\
\hline 2014 & $32,7 \%$ & $71,7 \%$ & $69,7 \%$ & $47,9 \%$ & 7.367 \\
\hline 2015 & $34,1 \%$ & $66,6 \%$ & $66,0 \%$ & $42,5 \%$ & 7.274 \\
\hline 2016 & $32,2 \%$ & $71,8 \%$ & $70,3 \%$ & $50,9 \%$ & 7.035 \\
\hline 2017 & $33,3 \%$ & $80,1 \%$ & $80,8 \%$ & $59,0 \%$ & 5.850 \\
\hline Media & $23,3 \%$ & $67,6 \%$ & $66,0 \%$ & $42,6 \%$ & 7.066 \\
\hline
\end{tabular}

*1. Presupuesto aprobado antes del 31/12/(t-1). *2. Remisión de la liquidación del presupuesto antes del 31/03/(t+1). *3. Cuenta general aprobada en Pleno antes del 01/10/(t+1). *4. Cuenta general rendida antes del 15/10/(t+1). Fuente: elaboración y Portal de Rendición de Cuentas (https://bit.ly/2BMn4vs) [22 de febrero de 2019].

A pesar de la relevancia de lo expuesto, el grado efectivo de rendición de cuentas de las entidades locales en España y el cumplimiento de los plazos legales de tramita-

7 Conocidas como ISSAI-ES y disponibles en https://bit.ly/346vs56.

8 La delimitación exacta se encuentra en la introducción de las ISSAI-ES 100 a 400. Sobre esta precisión terminológica también se extiende Fernández Llera (2009). 
ción de la cuenta general y del presupuesto anual siguen siendo muy poco satisfactorios, como muestran las cifras de la tabla 2 , referidas en exclusiva al ámbito municipal. ${ }^{9}$

En promedio, en el periodo 2009-2017 el presupuesto anual sólo fue aprobado en plazo por menos de una cuarta parte de los ayuntamientos españoles, si bien en los últimos años la mejora ha sido sustancial, pero todavía muy insuficiente. Como muestra de este incumplimiento amplio y recurrente se puede citar el ejercicio 2014: solo un 34\% de los ayuntamientos aprobó el presupuesto en plazo; un 60\% lo hizo fuera de plazo (con un retraso medio que superó los cuatro meses); otro 4\% aprobó el presupuesto anual con el ejercicio ya vencido (lo cual, además de ilegal, es inútil); y el restante $2 \%$ ni siquiera aprobó presupuesto alguno (Tribunal de Cuentas, 2016). Extrapolando esas proporciones al conjunto de la planta municipal española, la realidad estaría mostrando que cada año unos 500 municipios se colocan en situación de clamorosa ilegalidad, otros 5000 aproximadamente trabajan con presupuestos mermados en su vigencia natural de 12 meses, y poco más de 2500 — sobre un total de 8000 - muestran un exacto cumplimiento del marco temporal del presupuesto anual. El daño sobre la transparencia y el buen gobierno es evidente, ya que la prórroga automática opera en miles de casos, muchos de ellos reiterado año tras año, lo que convierte esta institución jurídica de carácter extraordinario en algo habitual, desvirtuando la planificación, el control y la rendición de cuentas.

Por su parte, la aprobación de las liquidaciones presupuestarias sí muestra un mayor grado de cumplimiento del plazo, algo en lo que sin duda ha podido influir la restricción impuesta en la Ley 2/2011, de 4 de marzo, de Economía Sostenible, por la cual se podrían retener los fundamentales ingresos por la participación en los tributos del Estado a las entidades locales incumplidoras. Esta restricción ha impuesto un coste añadido por incumplimiento, ya que hasta su entrada en vigor la remisión de la liquidación presupuestaria quedaba muy desatendida en las prioridades gestoras. Con todo, el mejor dato de la serie supera por poco el 80\% (en 2017), lo que señala un amplio margen de mejora hasta lograr el total cumplimiento.

En tercer lugar, el cumplimiento del deber de aprobación de la cuenta general en el Pleno municipal muestra valores comparativamente elevados y crecientes en los últimos años, con un perfil casi idéntico al de la remisión de la liquidación, pero aquí sin que haya mediado una sanción añadida por incumplimiento. En otros trabajos (Fernández Llera, 2015) se ha defendido la oportunidad de que el debate plenario de la cuenta general no deje de sustanciarse, en virtud del principio democrático, pero al mismo tiempo se elimine el requisito de aprobación por mayoría, bastando la aprobación y posterior remisión — que no rendición en sentido estricto- a la ICEX por parte de la Alcaldía-Presidencia. Cabe recordar que la cuenta general, como imagen fiel de la gestión, previamente formada y validada por el órgano de control interno local, no debería admitir un voto en contra, si no es por razones políticas espurias. Más claro todavía: la oposición política debería poder votar contra la gestión realizada

9 El sector público local en España se compone de municipios, mancomunidades de municipios, entidades locales menores (submunicipales) y otras de índole superior o inferior. En todo caso, la significatividad del dato de los municipios es muy elevada, ya que suponen en torno al $80 \%$ del presupuesto del sector público local. 
por el gobierno local (moción de censura o cuestión de confianza) o contra la gestión planeada (planes estratégicos o presupuestos anuales), pero no contra la gestión registrada en los documentos contables, bajo la obvia premisa de su corrección técnica.

Finalmente, el índice de rendición de cuentas en plazo a las ICEX es bastante reducido, lo cual se entiende mejor tras constatar el grado de cumplimiento en las anteriores fases del ciclo presupuestario. También en este aspecto el avance ha sido sustancial en los últimos años, pero el índice del 100\% se antoja muy lejano aún. Las medidas coercitivas y sancionadoras aprobadas en los últimos años (entre otras, la citada infracción muy grave por falta de rendición de cuentas, o la exigencia de rendición de cuentas para que una entidad local pueda acceder a subvenciones) parecen haber surtido algún efecto, pero no todo el que cabría esperar. La cuestión clave reside entonces en el autoconvencimiento sobre el cumplimiento de todas las obligaciones legales a lo largo del ciclo presupuestario, así como en un control interno fiable. Aun así, cuando la persuasión no es suficiente, deben utilizarse mecanismos de probada eficacia, como son los informes de fiscalización específicos o la divulgación de los incumplimientos, a modo de sanción reputacional o política. Y, si aún no basta, entonces será preciso dar pasos adicionales hacia mecanismos coercitivos, de ejecución forzosa o sanción, sin perjuicio de la exigencia de responsabilidades administrativas o penales para responsables políticos y/o técnicos (Fernández Llera, 2015).

Tabla 3. Índices sintéticos de cumplimiento global de los municipios (\% del total)

\begin{tabular}{|l|c|c|c|c|}
\hline & $\begin{array}{c}\text { Promedio } \\
\text { simple"1 }\end{array}$ & $\begin{array}{c}\text { Con } \\
\text { ponderaciones } \\
\text { externas }\end{array}$ & $\begin{array}{c}\text { Con } \\
\text { ponderaciones } \\
\text { internas }\end{array}$ & $\begin{array}{c}\text { Municipios } \\
\text { considerados }^{* 1}\end{array}$ \\
\hline 2009 & $27,7 \%$ & $19,5 \%$ & $33,4 \%$ & 6.897 \\
\hline 2010 & $36,7 \%$ & $30,1 \%$ & $42,8 \%$ & 7.147 \\
\hline 2011 & $46,0 \%$ & $38,4 \%$ & $53,7 \%$ & 7.291 \\
\hline 2012 & $54,3 \%$ & $46,1 \%$ & $63,3 \%$ & 7.355 \\
\hline 2013 & $57,9 \%$ & $50,2 \%$ & $65,6 \%$ & 7.382 \\
\hline 2014 & $55,5 \%$ & $49,0 \%$ & $61,4 \%$ & 7.367 \\
\hline 2015 & $52,3 \%$ & $45,9 \%$ & $57,5 \%$ & 7.274 \\
\hline 2016 & $56,3 \%$ & $50,2 \%$ & $62,2 \%$ & 7.035 \\
\hline 2017 & $63,3 \%$ & $56,3 \%$ & $70,4 \%$ & 5.850 \\
\hline Media & $49,9 \%$ & $42,7 \%$ & $56,6 \%$ & 7.066 \\
\hline
\end{tabular}

*1. Cada ítem de cumplimiento pondera lo mismo (25\%). *2. Los ítems de cumplimiento ponderan, respectivamente, $31,25 \%, 18,75 \%, 6,25 \%$ y $43,75 \%$. *3. Los ítems de cumplimiento ponderan, respectivamente, $11,67 \%, 33,92 \%, 33,07 \%$ y $21,35 \%$. Fuente: elaboración propia y Portal de Rendición de Cuentas (https://bit.ly/2BMn4vs) [22 de febrero de 2019].

Tomando un índice simple de cumplimiento global por ejercicio (tabla 3), obviando el tamaño poblacional de los municipios — como por otra parte, hace la ley-y ponderando cada uno de los cuatro ítems de manera idéntica, se observa que 
el promedio para el periodo 2009-2017 no alcanza ni el 50\%, si bien desde 2012 ya se sitúa por encima de ese umbral, obteniéndose la mejor marca en el último ejercicio considerado. Sin embargo, parece plausible que para el gestor local no todos los cumplimientos revistan la misma importancia, ya sea por su importancia política diferencial o por la gravedad de las consecuencias institucionales, financieras y personales derivadas del incumplimiento. Por ello, se han construido dos índices sintéticos alternativos, modificando las ponderaciones de cada ítem.

En el primero, se ha incorporado ad hoc la ponderación más baja para la aprobación plenaria de la cuenta general, dado que su incumplimiento no tiene consecuencia alguna. Siguen en importancia la remisión de la última liquidación (en caso de incumplimiento, podría haber retención de fondos básicos), la aprobación en plazo del presupuesto (como documento estratégico de planificación anual) y, por último, como la más relevante, la rendición de la cuenta general en plazo (como culminación del ciclo de gestión presupuestaria, además, con graves consecuencias por incumplimiento). El índice global baja así hasta el $42.7 \%$ y solo supera el $50 \%$ en tres ejercicios de la serie.

En el segundo, para sortear la posible crítica por discrecionalidad o manipulabilidad del anterior, se utilizaron ponderaciones internas, calculadas a partir de las respectivas medias históricas de cumplimiento (periodo 2009-2017) en cada uno de los cuatro ítems. De este modo, se incorpora con robustez la preferencia revelada sobre la importancia atribuida a cada uno de ellos. Con esta ordenación, la remisión de la liquidación se coloca como la cuestión más importante, casi al mismo nivel que la aprobación plenaria de la cuenta general (en este último caso, probablemente, por su mayor facilidad, no tanto por su valoración subjetiva), seguidas de la rendición de la cuenta general y, por último, la aprobación del presupuesto anual, convertido de este modo en el ítem de cumplimiento menos relevante. El índice global se eleva así hasta el $56.6 \%$, con solo dos ejercicios por debajo del $50 \%$ y con un techo en el último año considerado del $70.4 \%$.

Indagando en las causas de la baja rendición de cuentas, las ICEX suelen concluir en sus informes horizontales que no siempre esa carencia responde a un único patrón, ni siquiera a parámetros objetivos, relacionados con el tamaño de la jurisdicción. Antes bien, como se muestra en la tabla 4, los motivos alegados son múltiples, lo que hace pensar más bien en un falta de cultura asentada de transparencia y rendición de cuentas, envuelta en un catálogo de excusas, disculpas o pretextos ${ }^{10}$ que no alcanzan el concepto de alegación, tal y como se entiende este último concepto en auditoría. En la mayoría de entidades locales la falta de recursos humanos es la principal motivación expuesta, aunque ha descendido su importancia relativa, a favor de un perfil más diversificado de razones, incluyendo el retraso por falta de aprobación de las cuentas de entidades dependientes (9\% en 2016), las incidencias informáticas derivadas del uso de nuevas plataformas telemáticas o renovados planes de contabilidad ( $9 \%$ en 2016), e incluso la ausencia de causa concreta alguna (14\% en 2016). De otro lado, los problemas de falta de acuerdo plenario de aprobación de

10 Cuando no ataques a la ICEX por parte del fiscalizado, sobre una supuesta falta de empatía (https://bit. ly/2PpAmpR). 
la cuenta general, junto a la ausencia o cambio del interventor local como encargado de formar la cuenta general, son fácilmente subsanables si se prescinde de dicho trámite político y/o se cuenta con apoyo y asistencia en todo momento para las tareas de control interno local.

Tabla 4. Causas generales de la no rendición de la cuenta general en plazo

\begin{tabular}{|l|l|l|l|}
\hline Incidencias informáticas & $\mathbf{2 0 1 4}$ & $\mathbf{2 0 1 5}$ & $\mathbf{2 0 1 6}$ \\
\hline Falta de aprobación de las cuentas de entidades dependientes & $3 \%$ & $\mathbf{1 0} \%$ & $\mathbf{9} \%$ \\
\hline Falta de recursos humanos & $\mathbf{3} \%$ & $\mathbf{6} \%$ & $\mathbf{9} \%$ \\
\hline Falta de recursos materiales & $0 \%$ & $5 \%$ & $48 \%$ \\
\hline Falta acuerdo Pleno / Ausencia o cambio interventor local & $7 \%$ & $19 \%$ & $13 \%$ \\
\hline Retraso en liquidación de presupuestos & $7 \%$ & $4 \%$ & $5 \%$ \\
\hline Sin causa concreta & $7 \%$ & $8 \%$ & $14 \%$ \\
\hline
\end{tabular}

Nota: las cifras se refieren al conjunto de las entidades locales, no solo ayuntamientos, si bien las diferencias son muy poco significativas, dado que estos últimos suponen el $80 \%$ del sector público local. Fuente: Tribunal de Cuentas (2018).

Como colofón a este epígrafe, es preciso volver a recordar un compendio de recomendaciones de las ICEX (en particular: Tribunal de Cuentas, 2003, 2014) que, por su relevancia y reiteración durante varios años, ${ }^{11}$ quedan revestidas de evidente perentoriedad:

- Homogeneización normativa de los plazos de rendición de las cuentas de las entidades locales en toda España, estableciendo como referencia general la fecha del 30 de junio del ejercicio siguiente al que las cuentas se refieran.

- Fomento de medidas legislativas tendentes a la reducción de los plazos actuales de tramitación y rendición de presupuestos y cuentas generales locales, tratando de mejorar la planificación económico-financiera y de aproximar la rendición de cuentas y su control a la gestión de referencia, con criterios de transparencia y oportunidad.

- Establecimiento de mecanismos y procedimientos internos en las entidades locales para asegurar un adecuado seguimiento del ciclo presupuestario y del proceso de rendición de sus cuentas generales, para que se realicen en plazo.

- Fortalecimiento de la obligación de rendición de cuentas en tiempo y forma mediante medidas legislativas que impliquen consecuencias efectivas de inmediata y directa aplicación en caso de incumplimiento. En particular, se destacan por su efectividad la actualización del importe de las multas coercitivas, y el estableci-

11 De igual modo, los informes de los órganos autonómicos de control externo y sendas declaraciones formales — de 21 de junio de 2017 — sobre modificaciones legales para promover la reducción de los plazos de rendición de cuentas del sector público y sobre las medidas para estimular la rendición de cuentas de las entidades locales (https://bit.ly/2MTOKoI). 
miento como requisito indispensable para el acceso de las entidades locales y sus entidades dependientes a ayudas y subvenciones públicas.

- Refuerzo personal y material de los órganos interventores locales, más aún, tras la entrada en vigor en 2018 del reglamento de control interno y del régimen jurídico de estos funcionarios.

- Intensificación del apoyo efectivo de las instancias supramunicipales, provinciales y autonómicas a las entidades locales — sobre todo a las más pequeñas- para que puedan cumplir en todos sus términos con la exigencia de rendición de cuentas.

- Revisión del mecanismo de aprobación plenaria de la cuenta general, para evitar que su eventual rechazo por motivos políticos implique un deterioro de la rendición de cuentas.

\section{Conclusiones y discusión}

El buen gobierno, la transparencia y la rendición de cuentas - ya sean estas últimas como modalidades del primero o como categorías propias- han dejado de ser simples aspiraciones o deberes públicos de menor rango, para transmutar en elevadas exigencias. Su cumplimiento implica tareas y consume recursos- esto es obvio- y su incumplimiento puede acarrear sanciones o medidas correctivas y coercitivas, pero en todo caso el bien superior se cuantifica en el beneficio social derivado de una gestión pública racional y transparente. Lo anterior es predicable del conjunto del sector público y de cada uno de sus integrantes, pero adquiere una importancia crucial en el ámbito local, por la multitud de entidades existentes, por su importancia en la prestación de servicios públicos básicos para la ciudadanía y, también, por el bajo índice de cumplimiento de las obligaciones presupuestarias y económico-financieras de rendición de cuentas.

Es preciso que el presupuesto y la cuenta general vuelvan a la agenda de prioridades, incluyendo su faceta política (como elementos de planificación, gestión y rendición de cuentas), técnica (con el refuerzo de los órganos de control interno y las ICEX) y académica (con solventes estudios doctrinales y empíricos sobre instituciones presupuestarias, al estilo de Alesina \& Perotti, 1996).

En la búsqueda de una completa rendición de cuentas, al margen de su exacta formalización en concretas normas jurídicas, éticas o de conducta, es preciso imbuir de esta cultura a todos los gestores públicos, así como a órganos e instituciones de control. Este es también el mandato amplio de los Objetivos de Desarrollo Sostenible de Naciones Unidas. En este marco, las conclusiones y recomendaciones presentadas para el caso español serían bastante extrapolables al ámbito de otros países de Iberoamérica, con las necesarias consideraciones que procedan en cada caso (Almeida Sánchez, 2014).

En España, la rendición de cuentas se ha regulado tradicionalmente en la legislación de Haciendas Locales y en su normativa derivada, junto a todas las cuestiones relativas a gastos e ingresos públicos, que sin duda han gozado de mayor interés y preponderancia política, subsumiendo las primeras en un cierto abandono. Quizás esa haya sido una de las causas por las que la más reciente legislación de transparencia y buen gobierno -tanto la estatal básica como la autonómica- también 
hayan preterido el refuerzo de esta obligación, pudiendo en su lugar haber concretado sus exigencias, mediante la incorporación de muchas de las reiteradas recomendaciones de las ICEX. De igual modo, en el ámbito local se precisa una mayor claridad en las normas y procedimientos internos que permitan cumplir con mayor eficacia las exigencias legales, adaptándose en particular al tamaño de cada administración concernida, dada la atomización municipal.

Existe un amplio margen de mejora para cumplir las vigentes obligaciones, lo que no impide seguir avanzando en la definición de nuevas exigencias que las superen, por ejemplo, para acercar en el tiempo la fiscalización a la gestión realizada, así como para mejorar la calidad de ambas. Serían signos inequívocos de calidad institucional, señales de responsabilidad y confiabilidad, y evidencia de ética, transparencia y buen gobierno.

\section{Apoyos y soporte financiero de la investigación}

El autor agradece los comentarios recibidos y el apoyo del grupo GEN (Governance and Economics research Network), de la Universidad de Vigo (España). Todas las opiniones son personales y no institucionales.

\section{Referencias}

Albalate del Sol, D. (2013). The institutional, economic and social determinants of local government transparency. Journal of Economic Policy Reform, 16(1), 90-107. http://doi.org/10. 1080/17487870.2012.759422.

Alesina, A., \& Perotti, R. (1996). Déficits presupuestarios e instituciones presupuestarias. Papeles de Economía Española, 68, 255-271.

Almeida Sánchez, M. D. (2014). Experiencias internacionales en transparencia fiscal, Macroeconomía del Desarrollo, 146. Comisión Económica para América Latina y el Caribe (Cepal) / Naciones Unidas.

Arapis, T., \& Reitano, V. (2018). Examining the evolution of cross-national fiscal transparency, Examining the evolution of cross-national fiscal transparency, The American Review of Public Administration, 48(6), 550-564. http://doi.org/10.1177/0275074017706740.

Barea Tejeiro, J. (1997). Disciplina presupuestaria e integración de España en la Unión Monetaria. Madrid, España: Real Academia de Ciencias Morales y Políticas.

Bassols Coma, M. (2015). Buen gobierno, ética pública y altos cargos. Revista Española de Derecho Administrativo, 172, 27-60.

Bearfield, D. A., \& Bowman, A. O. (2017). Can you find it on the web? An assessment of municipal e-government transparency. The American Review of Public Administration, 47(2), 172-188. http://doi.org/10.1177/0275074015627694.

Caamaño-Alegre, J., Lago-Peñas, S., Reyes-Santias, F., \& Santiago-Boubeta, A. (2013). Budget transparency in local governments: An empirical analysis. Local Government Studies, 39(2), 182-207. http://doi.org/10.1080/03003930.2012.693075.

Campos Acuña, M. C. (2014). Las entidades locales ante las obligaciones de transparencia. Una primera aproximación a la Ley 19/2013, de transparencia, acceso a la información pública y buen gobierno. Revista Digital CEMCI, 23, 1-30.

Campos Acuña, M. C., \& Caamaño Alegre, J. (2015). Abriendo puertas y ventanas de los ayuntamientos gallegos. Más transparencia para un mejor gobierno local. Documento Red Localis, 2/2015. Recuperado de: https://bit.ly/2qTg3H9 [Fecha de consulta: 1 de agosto de 2019].

Cárcaba García, A., \& García-García, J. (2010). Determinants of online reporting of accounting 
information by Spanish local government authorities, Local Government Studies, 36(5), 679-695. http://doi.org/10.1080/03003930.2010.506980.

Comisión Europea (2001). La gobernanza europea. Un Libro Blanco. Luxemburgo, Luxemburgo, $\operatorname{COM}(2001) 428$ final.

Descalzo González, A. (2017). El buen gobierno de los altos cargos. Revista General de Derecho Administrativo, 44.

Esteller-Moré, A., \& Polo Otero, J. (2012). Fiscal transparency. (Why) doesyourlocal governmentrespond? Public ManagementReview, 14(8),1153-1173.http://doi.org/10.1080/14719037.2012. 657839.

FEMP (2015). Código de Buen Gobierno Local FEMP. Recuperado de: https://bit.ly/2qJSxvZ [Fecha de consulta: 1 de julio de 2019].

Fernández Llera, R. (2009). Fiscalización de la gestión pública en los órganos de control externo de las comunidades autónomas. Presupuesto y Gasto Público, 57, 135-154.

Fernández Llera, R. (2015). Transparencia y rendición de cuentas locales tras la supuesta racionalización. Presupuesto y Gasto Público, 81, 131-150.

Frías Aceituno, J. V.; Marques, M. C., \& Rodríguez Ariza, L. (2013). Divulgación de información sostenible: ¿se adapta a las expectativas de la sociedad? Revista de Contabilidad, 16(2), 147-158. http://doi.org/10.1016/j.rcsar.2013.07.004.

García Jiménez, A. (2018). El empleado público como epicentro del buen gobierno. Revista General de Derecho Administrativo, 49, 1-45.

García Pelayo, M. (2009). Del mito y de la razón en la historia del pensamiento político. En M. García Pelayo, Obras completas II (pp. 1229-1240). Madrid, España: Centro de Estudios Políticos y Constitucionales.

García-Sánchez, I. M.; Frías-Aceituno, J. \& Rodríguez-Domínguez, L. (2013). Determinants of corporate social disclosure in Spanish local governments, Journal of Cleaner Production, 39, 60-72. http://doi.org/10.1016/j.jclepro.2012.08.037.

González García, J. M. (2016): La mirada de la justicia. Madrid, España: Antonio Machado Libros.

Guillamón, M. D.; Bastida, F., \& Benito, B. (2011). The determinants of local government's financial transparency. Local Government Studies, 37(4), 391-406. http://doi.org/10.1080/030 03930.2011 .588704$.

INAP (Instituto Nacional de Administración Pública) (2016). La normativa autonómica en materia de derecho de acceso a la información Pública. Madrid, España: INAP.

Irwin, T. C. (2013). Shining a light on the mysteries of State: The origins of fiscal transparency in Western Europe. IMF Working Papers, WP/13/219, 1-43.

Palomar Olmeda, A. (2014). La articulación general de la responsabilidad derivada de la gestión de fondos públicos. En VV.AA.: XVIII Jornadas de presupuestación, contabilidad y control público. Contabilidad, transparencia y responsabilidades públicas (pp. 249-285). Madrid, España: IGAE.

Ridao Martín, J. (2014). La regulación de la transparencia y del acceso a la información pública en la esfera autonómica. Un estudio comparado. Revista General de Derecho Constitucional, 19, 1-31.

Serrano-Cinca, C.; Rueda-Tomás, M., \& Portillo-Tarragona, P. (2009). Factors influencing e-disclosure in local public administrations, Environment and Planning C: Government and Policy, 27(2), 355-378. http://doi.org/10.1068/c07116r.

Skinner, Q. (2009): El artista y la filosofía política. El Buen Gobierno de Ambrogio Lorenzetti. Madrid, España: Trotta.

Suárez Pandiello, J., \& Fernández Llera, R. (2017). From legal transparency to good governance in the Spanish municipalities. En B. Cuadrado-Ballesteros e I. M García-Sánchez, (Eds.), Local governments in the digital era. Looking for accountability (pp. 113-130). Nueva York, Estados Unidos: Nova Science Publishers. 
Tejedo-Romero, F., \& Ferraz Esteves Araujo, J. F. (2018). Transparencia en los municipios españoles: determinantes de la divulgación de información. Convergencia, Revista de Ciencias Sociales, 78, 153-174. http://doi.org/10.29101/crcs.v25i78.9254.

Teré Peréz, A. (2015). La rendición de cuentas y la remisión de los contratos de las entidades locales a las instituciones de control externo: la distinción entre deber y obligación. Auditoría Pública, 66, 93-104.

Tribunal de Cuentas (2003). Moción relativa a las posibles soluciones legales y administrativas para que las entidades locales rindan sus cuentas de forma completa y en los plazos legalmente establecidos, Recuperado de: https://bit.ly/2JsQGlE [Fecha de consulta: 15 de septiembre de 2019].

Tribunal de Cuentas (2013). Normas de fiscalización del Tribunal de Cuentas, aprobadas por el Pleno el 23 de diciembre de 2013, Recuperado de: https://bit.ly/2JsQGlE [Fecha de consulta: 1 de octubre de 2019].

Tribunal de Cuentas (2014). Informe sobre actuaciones del Tribunal de Cuentas para promover la rendición de cuentas en el ámbito local, Recuperado de https://bit.ly/2JsQGlE [Fecha de consulta: 1 de octubre de 2019].

Tribunal de Cuentas (2016). Informe de fiscalización del sector público local, ejercicio 2014. Recuperado de: https://bit.ly/2JsQGlE [Fecha de consulta: 10 de octubre de 2019].

Tribunal de Cuentas (2018). Fiscalización sobre la rendición de cuentas de las entidades locales, ejercicio 2016, con especial atención a entidades con incumplimientos reiterados de dicha obligación. Recuperado de: https://bit.ly/2JsQGlE [Fecha de consulta: 10 de agosto de 2019].

Vila i Vila, J. (2013). Determinantes de la transparencia contable en los municipios. Auditoría Pública, 60, 57-64.

Villoria Mendieta, M. (2014). La transparencia como política pública en el nivel local. Revista Democracia y Gobierno Local, 26/27, 4-16.

Wang, R. F. et al. (2015). Trends in fiscal transparency: Evidence from a new database of the coverage of fiscal reporting. IMF Working Papers, WP/15/188, 1-37. 